\title{
Controlling DNA-end resection: a new task for CDKs
}

\section{Lorenza P. Ferretti ${ }^{\dagger}$, Lorenzo Lafranchi ${ }^{\dagger}$ and Alessandro A. Sartori *}

Institute of Molecular Cancer Research, Faculty of Medicine, University of Zurich, Zurich, Switzerland

\section{Edited by:}

Antonio Porro, Ecole Polytechnique

Federale de Lausanne, Switzerland

\section{Reviewed by:}

Travis H. Stracker, Institute for Research in Biomedicine, Spain Boris Pfander, Max-Planck Society, Germany

\section{${ }^{*}$ Correspondence:}

Alessandro A. Sartori, Institute of Molecular Cancer Research, Faculty of Medicine, University of Zurich, Winterthurerstrasse 190,

CH-8057 Zürich, Switzerland e-mail: sartori@imcr.uzh.ch

${ }^{\dagger}$ These authors have contributed equally to this work.
DNA double-strand breaks (DSBs) are repaired by two major pathways: homologous recombination (HR) and non-homologous end-joining (NHEJ). The choice between HR and NHEJ is highly regulated during the cell cycle. DNA-end resection, an evolutionarily conserved process that generates long stretches of single-stranded DNA, plays a critical role in pathway choice, as it commits cells to HR, while, at the same time, suppressing NHEJ. As erroneous DSB repair is a major source of genomic instability-driven tumorigenesis, DNA-end resection factors, and in particular their regulation by post-translational modifications, have become the subject of extensive research over the past few years. Recent work has implicated phosphorylation at S/T-P motifs by cyclin-dependent kinases (CDKs) as a major regulatory mechanism of DSB repair. Intriguingly, CDK activity was found to be critically important for the coordinated and timely execution of DNA-end resection, and key players in this process were subsequently identified as CDK substrates. In this mini review, we provide an overview of the current understanding of how the DNA-end resection machinery in yeast and human cells is controlled by CDK-mediated phosphorylation.

Keywords: DNA double-strand break repair, DNA-end resection, homologous recombination, cyclin-dependent kinase, phosphorylation, CtIP/Sae2, PIN1

\section{INTRODUCTION}

In order to preserve genome integrity, cells employ a complex surveillance network that detects, signals and repairs DNA lesions. These intricate and highly regulated pathways are collectively termed the DNA damage response (DDR; Zhou and Elledge, 2000). One major hallmark of the DDR represents the activation of checkpoints to temporarily delay cell cycle progression through inhibition of cyclin-dependent kinase (CDK) activity. In the budding yeast Saccharomyces cerevisiae, a single CDK, Cdc28 (or Cdk1), drives both G1/S and G2/M transitions, whereas in metazoan four CDKs are responsible for cell cycle progression (Morgan, 1997). CDK activity is modulated by association with regulatory subunits known as cyclins, the levels of which oscillate during the cell cycle (King et al., 1996). G1 phase is controlled by CDK4 and CDK6 in complex with D-type cyclins, whereas CDK2-cyclin E is essential for G1/S transition and the assembly of the DNA replication machinery. CDK2-cyclin A is required for proper completion of DNA replication and progression through $\mathrm{S}$ phase. Toward the end of interphase, cyclin $\mathrm{A}$ associates with CDK1 to facilitate S/G2 transition before CDK1cyclin B complexes drive cells through mitosis (Morgan, 1997; Malumbres and Barbacid, 2005). CDKs belong to a large family of proline-directed kinases (which also includes MAPKs and GSK3) that exclusively phosphorylate serines or threonines immediately preceding a proline (S/T-P motifs) (Hanks and Hunter, 1995; Errico et al., 2010). CDK substrate specificity is increased by direct binding of the cyclin subunit to conserved RxL motifs present in certain CDK targets (Harper and Adams, 2001). A recent study showed that $50 \%$ of CDK2-cyclin A targets carried at least one RxL motif distal to the phosphorylation site (Chi et al., 2008).
In accordance with reduced CDK activity as a consequence of DNA damage-induced checkpoint activation, S/T-P motifs are largely dephosphorylated in response to DNA double-strand breaks (DSBs) (Bennetzen et al., 2010; Beli et al., 2012). However, in apparent contrast to this, CDK activity is strictly required for accurate processing and repair of DSBs in S/G2 phase, indicating that at least some DDR factors are primed by CDK phosphorylation prior to checkpoint activation (Enserink and Kolodner, 2010; Chapman et al., 2012). DSBs are highly deleterious lesions with the potential to cause cell death or genomic instability leading to cancer. DSBs can arise spontaneously as a result of replication fork collapse or can be induced by exogenous DNA-damaging agents including ionizing radiation and certain anti-cancer drugs (Jackson and Bartek, 2009). In order to repair DSBs, all organisms rely on two major pathways: non-homologous end-joining (NHEJ) and homologous recombination (HR). NHEJ functions throughout the cell cycle and religates broken ends without the need of extensive processing (Lieber, 2010). HR, instead, requires an undamaged template for faithful DSB repair, usually the sister chromatid, and is therefore restricted to S/G2 phase (Heyer et al., 2010). HR is initiated by $5^{\prime}-3^{\prime}$ degradation of the DSB ends to generate $3^{\prime}$-single-stranded DNA (ssDNA) overhangs. This evolutionarily conserved process, termed DNA-end resection, requires the coordinated action of several nucleases and helicases (Figure 1; Mimitou and Symington, 2009; Blackwood et al., 2013). Recent work in yeast and human cells has established that DNA recombination and particularly DNA-end resection are highly regulated by various kinases including Mec1/ATR, Tel1/ATM, Rad53/CHK1, Cdc5/PLK1, and, as reviewed here, CDKs (Longhese et al., 2010; Chapman et al., 2012; Finn et al., 2012; Krejci et al., 2012). 


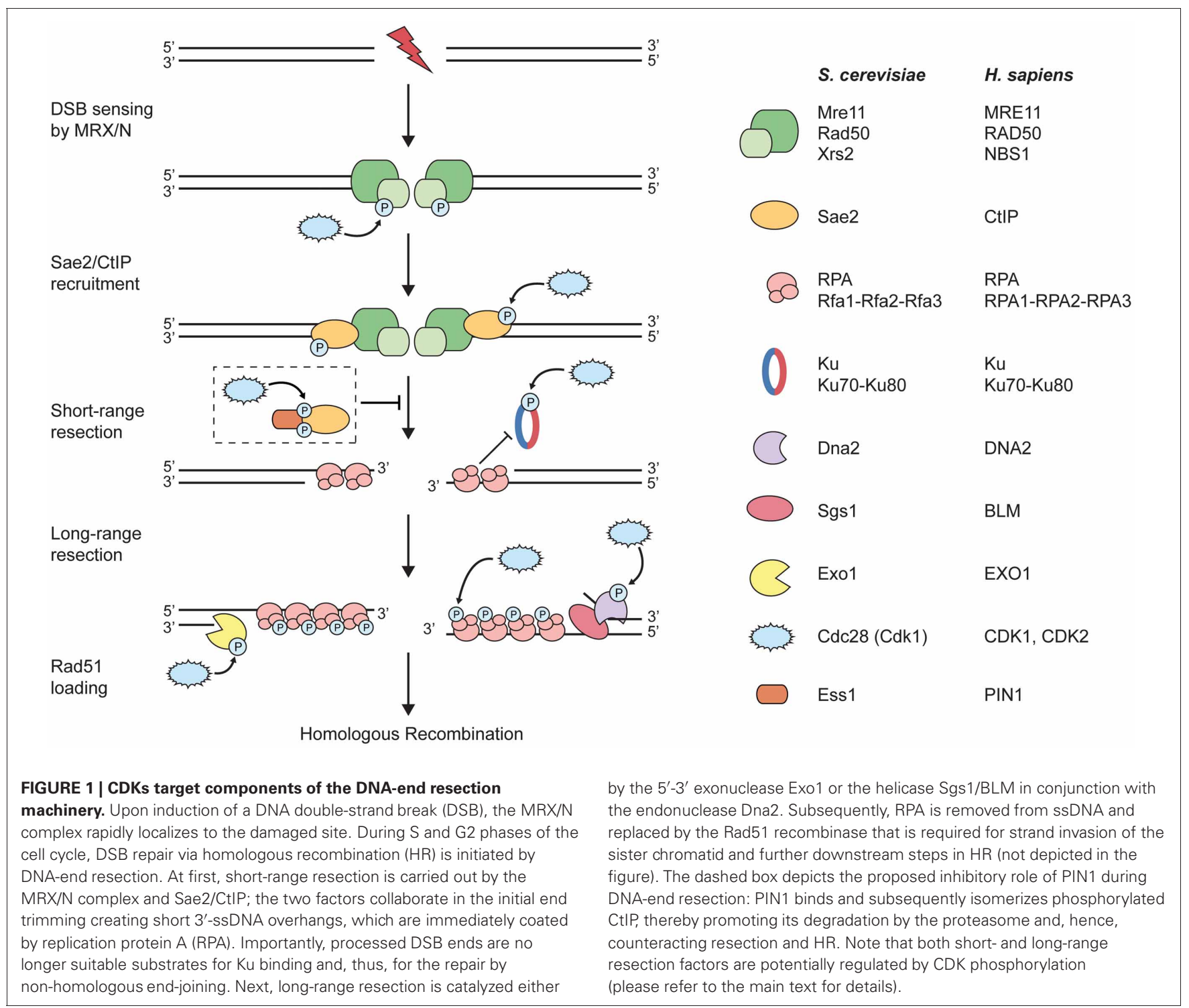

\section{CDK SUBSTRATES IN DNA-END RESECTION}

In 2004, two studies in S. cerevisiae described for the first time that Cdk1 is essential for DSB repair pathway choice by promoting DNA-end resection in G2 phase (Aylon et al., 2004; Ira et al., 2004). These findings were later confirmed in human cells, showing that ssDNA-dependent activation of the ATR checkpoint pathway in response to DSBs is restricted to S/G2 and requires CDK activity (Jazayeri et al., 2006). Similarly, inhibition of CDK2 in mammalian cells was shown to impair HR and delay DSB signaling (Deans et al., 2006). Based on these key findings, it was proposed that DNA-end resection is governed by CDK-mediated phosphorylation (Figure 1) (Ira et al., 2004). However, it was only until the last few years that components of the resection machinery were identified as CDK substrates.

\section{MRX/MRN}

Genetic studies in S. cerevisiae have long implicated the Mre11Rad50-Xrs2 (MRX) complex in the initial processing of DSBs
(Symington and Gautier, 2011). However, as MRX exhibits both endonuclease and $3^{\prime}-5^{\prime}$ exonuclease activities in vitro (Paull, 2010), it still remains unclear how MRX catalyzes $5^{\prime}-3^{\prime}$ nucleolytic degradation of DNA ends in vivo. New clues came from a recent study suggesting that DNA-end resection could occur with bidirectional polarity, as opposed to the unidirectional model shown in Figure 1. Accordingly, Mre11 endonuclease first creates a nick in the strand to be resected up to 300 nucleotides away from the DSB that, in a second step, serves as an entry point for resection by Mre11 3'-5' exonuclease toward the DSB end and by Exo1 5' $-3^{\prime}$ exonuclease away from the DSB (Garcia et al., 2011).

None of the MRX subunits have so far been reported as Cdk1 substrates. Moreover, an mre11 mutant in which all six S/T-P motifs have been mutagenized did not exhibit any major phenotypes attributable to a resection defect. The same holds true for an $x r s 2$ mutant in which both CDK consensus motifs (S/TP-x-K/R) were mutated (Ira et al., 2004). Notably, however, three additional S/T-P motifs in Xrs2 were found to be phosphorylated 
in a proteomic study, raising the possibility of it being indeed a Cdk1 substrate (Albuquerque et al., 2008). In human cells, akin to the situation in yeast, only the NBS1 subunit of the MRN complex was found to be phosphorylated in a cell-cycle-dependent manner (Figure 1; Olsen et al., 2010). Additionally, two groups reported that CDKs phosphorylate NBS1 at serine 432 in S phase (Falck et al., 2012; Wohlbold et al., 2012). Surprisingly, while Falck et al. concluded that NBS1-S432 phosphorylation promotes DNA-end resection, Wohlbold et al. reported normal resection in the absence of NBS1-S432 phosphorylation. Although it is rather difficult to reconcile these contradicting results, they have most likely emanated from the different NBS1-deficient cells used for complementation studies. Thus, it remains to be clarified whether Xrs2/NBS1 phosphorylation by CDKs is a conserved mechanism to promote DNA-end resection by MRX/N.

\section{Sae2/CtIP}

SAE2 (or COM1) was originally identified as being required to complete meiotic recombination in S. cerevisiae (McKee and Kleckner, 1997; Prinz et al., 1997). Subsequent genetic and biochemical studies in yeast and mammalian cells have shown that Sae2 and its human counterpart CtIP cooperates with the MRX/N nuclease to initiate resection of DSBs (Figure 1; Sartori et al., 2007; Symington and Gautier, 2011). There are three potential CDK phosphorylation sites in Sae2 and 12 in CtIP. Remarkably, phosphorylation of a single S/T-P motif in the Cterminus of both proteins (Sae2-S267/CtIP-T847) by CDK is required to promote resection (Huertas et al., 2008; Huertas and Jackson, 2009). Consistent with a role of Cdk1 in positively regulating Sae2 function, mutation of a RxL cyclin-binding motif present upstream of S267 caused comparable DNA damage hypersensitivity to that of sae2-S267A cells (Huertas et al., 2008). Moreover, in cells expressing a phospho-mimicking mutant (Sae2-S267E/CtIP-T847E), resection is permitted even in absence of Cdk1 activity; however, not to the same extent as in normal cells. Therefore, it was proposed that additional Cdk1 sites, on Sae2/CtIP itself or on other proteins, are required for optimal resection (Huertas, 2010). Despite the fact that the precise mechanism of how S267/T847 phosphorylation “activates" Sae2/CtIP is still unclear, it is of major importance for both meiotic and mitotic recombination (Manfrini et al., 2010; Nicolette et al., 2010).

Prior to the identification of CtIP-T847 as a CDK site, phosphorylation of S327 was shown to occur exclusively during S/G2 and to be a pre-requisite for CtIP-BRCA1 interaction ( $\mathrm{Yu}$ and Chen, 2004; Yu et al., 2006). Furthermore, it was recently shown that CtIP-S327 phosphorylation is CDK2-dependent and facilitated by MRE11, which directly interacts with CDK2 and CtIP, thereby bringing CDK2 in proximity with its substrate (Buis et al., 2012). Although evidence for a direct role of CtIP-S327 phosphorylation in resection is still missing, the BRCA1-CtIP complex was recently reported to facilitate the removal of the 53BP1 effector protein RIF1 from DSBs in S/G2, thereby channeling DSB repair into HR (Escribano-Díaz et al., 2013). Moreover, it was recently reported that phosphorylation of a cluster of five additional $\mathrm{S} / \mathrm{T}$-P motifs located in the central region of CtIP is important for DNA-end resection (Wang et al., 2013). Mechanistically, phosphorylation of this cluster is needed for the association of CtIP with NBS1, which promotes DNA damage-induced CtIP phosphorylation by ATM (You et al., 2009; Wang et al., 2013). It is important to note, however, that Wang et al. did not directly address whether any of these clustered phosphosites in CtIP are indeed targeted by CDKs in vivo.

\section{KU}

When DSBs arise in the cell, $\mathrm{Ku}-\mathrm{a}$ heterodimer composed of Ku70 and Ku80 - is usually loaded onto duplex DNA ends. During the repair process, Ku serves as a docking site for many NHEJ proteins, including DNA-PKcs and DNA ligase IV, to rejoin the broken ends (Lieber, 2010). It has been shown that DNA-end resection and $\mathrm{HR}$ are constrained during G1 due to both efficient NHEJ and low CDK activity (Aylon et al., 2004; Jazayeri et al., 2006). Interestingly, in the absence of $\mathrm{Ku}, \mathrm{Cdk} 1$ activity is dispensable for the initiation of resection by MRX-Sae2, but is still needed for long-range resection by Exo1 or Sgs1-Dna2 (Clerici et al., 2008). Therefore, $\mathrm{Ku}$ is thought to antagonize DNA-end resection and has to be removed from the ends in order to permit HR. These data also indicate that CDK activity promotes resection by restraining the recruitment of $\mathrm{Ku}$ to DSBs, raising the question whether $\mathrm{Ku}$ itself is a potential CDK substrate (Figure 1). However, removal of all putative Cdk1 phosphorylation sites on Ku70 and 3 out of 4 sites on Ku80 failed to elicit any DSB repair phenotype in $S$. cerevisiae, suggesting that the negative regulation of $\mathrm{Ku}$ by Cdk1 is most likely indirect (Zhang et al., 2009). Ku binding to DNA ends also attenuates resection and HR in mammalian cells (Shao et al., 2012; Tomimatsu et al., 2012). Furthermore, Ku70 was reported as a binding partner and substrate of CDK2-cyclin A, and Ku70-T455 was identified as a CDK target site by mass spectrometry (Müller-Tidow et al., 2004; Chi et al., 2008; Olsen et al., 2010); but whether or not Ku phosphorylation by CDKs has an impact on DNA-end resection has yet to be determined.

\section{EX01}

Exonuclease 1 (Exo1) belongs to the RAD2/XPG family of structure-specific $5^{\prime}$ nucleases and has been implicated in multiple genome maintenance pathways including DNA repair and telomere maintenance (Tran et al., 2004). Exol is dispensable for initial resection in yeast and human cells but acts in a separate pathway from Sgs1-Dna2/BLM-DNA2 to promote extensive 5'-3' DSB resection (Figure 1; Symington and Gautier, 2011). Moreover, Exo1-dependent resection and its recruitment to DSBs depends on both MRX/N and Sae2/CtIP and is blocked by the presence of $\mathrm{Ku}$ (Eid et al., 2010; Sun et al., 2012; Tomimatsu et al., 2012). Although DNA damage-induced phosphorylation of Exo1 has been reported to attenuate its activity in both yeast and human cells (Morin et al., 2008; Bolderson et al., 2010), probably by controlling its stability (El-Shemerly et al., 2005), there is currently no published data available whether Exol is a CDK target. However, several S/T-P sites in human EXO1 were repeatedly found to be phosphorylated using mass spectrometry analyses (El-Shemerly et al., 2008; Chen et al., 2009; Shiromizu et al., 2013). Indeed, some of these sites are phosphorylated by CDKs in S/G2 phase, thereby stimulating DNA-end resection by EXO1 and 
promoting DSB repair by HR while at the same time suppressing NHEJ (S. Burma, personal communication).

\section{Sgs1-Dna2/BLM-DNA2}

Sgs1 and its human ortholog BLM are members of the RecQ family of $3^{\prime}-5^{\prime}$ DNA helicases and are involved in the suppression of crossovers by promoting the dissolution of Holliday junction intermediates (Bernstein et al., 2010). The role for Sgs1 in conjunction with the Dna2 nuclease in the generation of long stretches of ssDNA during HR was discovered because of its redundancy with Exo1 (Figure 1; Gravel et al., 2008; Mimitou and Symington, 2008; Zhu et al., 2008). Although there is currently no data available on CDK-mediated phosphorylation of Sgs1, BLM is phosphorylated at various S/T-P motifs by mitotic kinases including CDK1 (Beausoleil et al., 2004; Leng et al., 2006; Dephoure et al., 2008; Olsen et al., 2010). However, these modifications are more likely to be involved in the regulation of BLM's function in the separation of sister chromatids during mitosis rather than in DNA-end resection (Chan and Hickson, 2011). In contrast, Cdk1-mediated phosphorylation of S. cerevisiae Dna2 at T4, S17, and S237 stimulates its recruitment to DSBs and DNA-end resection (Chen et al., 2011). Consistent with the redundancy observed between Dna2- and Exo1-dependent resection pathways, dna2-T4A/S17A/S237A cells only resect DSBs in the presence of functional Exo1. Interestingly, T4 and S17 lie within a bipartite nuclear localization signal, suggesting a timely regulated nuclear import of Dna2 upon phosphorylation during G1/S transition (Kosugi et al., 2009). Remarkably, human DNA2 lacks the entire N-terminal region of yeast Dna2 including all three S/T-P sites, suggesting that CDK-mediated regulation of long-range resection in human cells differs from yeast.

\section{RPA}

Replication protein A (RPA) is an evolutionarily conserved, heterotrimeric complex consisting of RPA1, RPA2, and RPA3. Owing to its high ssDNA binding affinity, RPA is required for most aspects of DNA metabolism including replication, repair and recombination (Oakley and Patrick, 2010). Following resection, RPA wraps around the generated 3 -ssDNA overhangs to protect the DNA against nuclease degradation and to prevent hairpin formation that would impede Rad51 filament assembly (Figure 1; Holloman, 2011). In vitro studies have also implicated RPA in promoting long-range resection through stimulation of both Exo1- and Sgs1-Dna2-dependent pathways (Cejka et al., 2010; Niu et al., 2010; Nimonkar et al., 2011; Cannavo et al., 2013). Furthermore, under DNA-damaging conditions, RPA-coated ssDNA serves to recruit the Mecl/ATR kinase, a critical event in checkpoint activation (Zou and Elledge, 2003). RPA2 contains a flexible N-terminal domain that is differentially phosphorylated at multiple residues during the cell cycle and in response to genotoxic stress. Two residues within this region, S23 and S29, are phosphorylated by CDK2-cyclin A and CDK1cyclin B at the G1/S boundary and during mitosis, respectively (Figure 1); however, they are not conserved in yeast (Oakley and Patrick, 2010). In response to DSBs, ATR-mediated phosphorylation of RPA2-S33 induces phosphorylation of RPA2-S23/S29, and both act synergistically to stimulate phosphorylation of additional residues closer to the N-terminus by DNA-PK (Anantha et al., 2007; Liaw et al., 2011). Although DNA damage-induced RPA2 hyper-phosphorylation seems critical for Rad51 recruitment and $\mathrm{HR}$ in response to replication stress, it is not essential for HR as measured by an I-SceI-based reporter assay (Shi et al., 2010; Serrano et al., 2013). Moreover, dephosphorylation of RPA2 by the PP4 phosphatase complex has also been reported to facilitate HR (Lee et al., 2010). However, a direct role of CDK-mediated RPA phosphorylation in DNA-end resection has not yet been demonstrated.

\section{CHROMATIN BINDING AND REMODELLING FACTORS}

DNA-end resection occurs in the context of chromatin, which constitutes a natural barrier to all kind of DNA transactions including DSB repair (Price and D'Andrea, 2013; Tsabar and Haber, 2013). Last year, three groups described a role of the $S$. cerevisiae chromatin-remodeling factor Fun30 (and its human counterpart SMARCAD1) in the repair of DSBs by HR (Chen et al., 2012; Costelloe et al., 2012; Eapen et al., 2012). Fun30/SMARCAD1 physically associates with DSB ends and, by weakening the histone-DNA interactions in nucleosomes, establishes a DNA conformation that facilitates both Sgs1- and Exo1-dependent resection. Furthermore, it was shown that Fun30 function in resection becomes less important in cells lacking the histone-bound Rad9 checkpoint protein, suggesting that Fun30 helps to overcome the inhibitory effect of Rad9 on DNA-end resection (Chen et al., 2012). Interestingly, both Fun30 and Rad9 were identified as Cdk1 substrates and reported to be phosphorylated at multiple S/T-P sites (Ubersax et al., 2003; Albuquerque et al., 2008). Moreover, loss of Rad9 has been reported to partially bypass the requirement for Cdk1 in resection (Lazzaro et al., 2008). This inhibitory mechanism is likely to be evolutionarily conserved as 53BP1, the mammalian ortholog of Rad9 (Wang et al., 2002), suppresses resection to promote NHEJ and immunoglobulin class switching (Bunting et al., 2010; Bothmer et al., 2011). Accordingly, multiple CDK consensus sites in SMARCAD1 and 53BP1 were repeatedly found to be phosphorylated (Beausoleil et al., 2004; Linding et al., 2007; Bennetzen et al., 2010; Olsen et al., 2010; Shiromizu et al., 2013). Further experiments are required to establish whether some of the CDK sites in Fun30/SMARCAD1 and Rad9/53BP1 play a role in the regulation of DNA-end resection and, thus, in DSB repair pathway choice.

\section{CONCLUDING REMARKS}

While the role of CDKs in regulating DNA-end resection is a given fact, we are only beginning to understand the mechanistic consequences of these phosphorylation events for individual repair factors, e.g., on protein-protein interactions, intracellular localization, or protein stability. Another important question to address in the future is how DNA-end resection is limited in order to generate confined tracts of ssDNA that are suitable for homology search by the Rad51 recombinase leading to productive HR. In other words, there must be additional regulatory mechanisms providing a switch between activation and inhibition of DNA-end resection to coordinate DSB repair pathways in a spatiotemporal manner. 
Novel insights are provided by a recent study showing that PIN1, a phosphorylation-specific peptidyl-prolyl cis/trans isomerase, counteracts DNA-end resection in human cells (Steger et al., 2013). PIN1 was previously shown to isomerize phosphorylated S/T-P peptide bonds, thereby controlling the function of a subset of CDK substrates involved in diverse cellular processes (Liou et al., 2011). In a proteomic screen for PIN1 substrates, Steger et al. identified several prominent DSB repair proteins including BRCA1, 53BP1 and CtIP. Interestingly, PIN1-mediated isomerization of CtIP requires the phosphorylation of CtIP at two S/T-P sites: CtIP-pT315 (by CDK) serves as the major binding site for PIN1, whereas CtIP-pS276 (by an unknown proline-directed kinase) is isomerized by PIN1. Following isomerization, CtIP gets ubiquitylated and subsequently degraded by the proteasome. In this way, PIN1 is proposed to limit DNA-end resection, thereby possibly contributing to fine-tune the coordination of $\mathrm{HR}$ and NHEJ during $S$ and G2 phases of the cell cycle (Figure 1; Karanam et al., 2012). So far, no direct connection has been made between

\section{REFERENCES}

Albuquerque, C. P., Smolka, M. B., Payne, S. H., Bafna, V., Eng, J., and Zhou, H. (2008). A multidimensional chromatography technology for in-depth phosphoproteome analysis. Mol. Cell. Proteomics 7, 1389-1396. doi: 10.1074/mcp.M700468-MCP200

Anantha, R. W., Vassin, V. M., and Borowiec, J. A. (2007). Sequential and synergistic modification of human RPA stimulates chromosomal DNA repair. J. Biol. Chem. 282, 35910-35923. doi: 10.1074/jbc.M704645200

Aylon, Y., Liefshitz, B., and Kupiec, M. (2004). The CDK regulates repair of double-strand breaks by homologous recombination during the cell cycle. EMBO J. 23, 4868-4875. doi: 10.1038/sj.emboj.7600469

Beausoleil, S. A., Jedrychowski, M., Schwartz, D., Elias, J. E., Villén, J., Li, J., et al. (2004). Large-scale characterization of HeLa cell nuclear phosphoproteins. Proc. Natl. Acad. Sci. U.S.A. 101, 12130-12135. doi: 10.1073/pnas.0404720101

Beli, P., Lukashchuk, N., Wagner, S. A., Weinert, B. T., Olsen, J. V., Baskcomb, L., et al. (2012). Proteomic investigations reveal a role for RNA processing factor THRAP3 in the DNA damage response. Mol. Cell 46, 212-225. doi: 10.1016/j.molcel.2012.01.026

Bennetzen, M. V., Larsen, D. H., Bunkenborg, J., Bartek, J., Lukas, J., and Andersen, J. S. (2010). Sitespecific phosphorylation dynamics of the nuclear proteome during the DNA damage response. Mol. Cell. Proteomics 9, 1314-1323. doi: 10.1074/mcp.M900616-MCP200
Bernstein, K. A., Gangloff, S., and Rothstein, R. (2010). The RecQ DNA helicases in DNA repair. Annu. Rev. Genet. 44, 393-417. doi: 10.1146/ annurev-genet-102209-163602

Blackwood, J. K., Rzechorzek, N. J., Bray, S. M., Maman, J. D., Pellegrini, L., and Robinson, N. P. (2013). Endresection at DNA double-strand breaks in the three domains of life. Biochem. Soc. Trans. 41, 314-320. doi: 10.1042/BST20120307

Bolderson, E., Tomimatsu, N., Richard, D. J., Boucher, D., Kumar, R., Pandita, T. K., et al. (2010). Phosphorylation of Exol modulates homologous recombination repair of DNA double-strand breaks. Nucleic Acids Res. 38, 1821-1831. doi: 10.1093/nar/gkp1164

Bothmer, A., Robbiani, D. F., Di Virgilio, M., Bunting, S. F., Klein, I. A., Feldhahn, N., et al. (2011). Regulation of DNA end joining, resection, and immunoglobulin class switch recombination by 53BP1. Mol. Cell 42, 319-329. doi: 10.1016/j.molcel.2011.03.019

Buis, J., Stoneham, T., Spehalski, E., and Ferguson, D. O. (2012). Mre11 regulates CtIP-dependent double-strand break repair by interaction with CDK2. Nat. Struct. Mol. Biol. 19, 246-252. doi: 10.1038/nsmb.2212

Bunting, S. F., Callen, E., Wong, N., Chen, H.-T., Polato, F., Gunn, A., et al. (2010). 53BP1 inhibits homologous recombination in Brcal-deficient cells by blocking resection of DNA breaks. Cell 141, 243-254. doi: 10.1016/j.cell.2010.03.012

Cannavo, E., Cejka, P., and Kowalczykowski, S. C. (2013).

PIN1 and the regulation of DSB repair in S. cerevisiae, studies of which are hampered by the fact that yeast PIN1 (Ess1) is essential for viability (Siepe and Jentsch, 2009). Future studies will have to determine whether phosphorylation-dependent regulation by PIN1 in concert with CDKs applies to other DSB repair proteins apart from CtIP and, thus, represents a general feature of the DDR.

\section{ACKNOWLEDGMENTS}

We wish to thank D. Hühn and P. Cejka for critical reading of the manuscript and helpful discussions. We also would like to apologize to all authors whose significant contributions could not be cited due to space limitations. This applies in particular to studies on DNA-end resection in Schizosaccharomyces pombe and in Xenopus laevis egg extracts. Alessandro A. Sartori is supported by the Vontobel-Stiftung. Lorenza P. Ferretti and Lorenzo Lafranchi are supported by grants of the Swiss National Science Foundation (31003A_135507) and the Promedica Stiftung.

Relationship of DNA degradation by Saccharomyces cerevisiae exonuclease 1 and its stimulation by RPA and Mre11-Rad50-Xrs2 to DNA end resection. Proc. Natl. Acad. Sci. U.S.A. 110, E1661-E1668. doi: 10.1073/pnas. 1305166110

Cejka, P., Cannavo, E., Polaczek, P., Masuda-Sasa, T., Pokharel, S., Campbell, J. L., et al. (2010). DNA end resection by Dna2Sgs1-RPA and its stimulation by Top3-Rmil and Mre11-Rad50Xrs2. Nature 467, 112-116. doi: 10.1038/nature09355

Chan, K. L., and Hickson, I. D. (2011). New insights into the formation and resolution of ultrafine anaphase bridges. Semin. Cell Dev. Biol. 22, 906-912. doi: 10.1016/j.semcdb.2011.07.001

Chapman, J. R., Taylor, M. R. G., and Boulton, S. J. (2012). Playing the end game: DNA doublestrand break repair pathway choice. Mol. Cell 47, 497-510. doi: 10.1016/j.molcel.2012.07.029

Chen, R. Q., Yang, Q. K., Lu, B. W., Yi, W., Cantin, G., Chen, Y. L., et al. (2009). CDC25B mediates rapamycin-induced oncogenic responses in cancer cells. Cancer Res. 69, 2663-2668. doi: 10.1158/00085472.CAN-08-3222

Chen, X., Cui, D., Papusha, A., Zhang, X., Chu, C. D., Tang, J., et al. (2012). The Fun30 nucleosome remodeller promotes resection of DNA doublestrand break ends. Nature 489, 576-580. doi: 10.1038/nature 1355

Chen, X., Niu, H., Chung, W.H., Zhu, Z., Papusha, A., Shim, E. Y., et al. (2011). Cell cycle regulation of DNA double-strand break end resection by Cdk1-dependent
Dna2 phosphorylation. Nat. Struct. Mol. Biol. 18, 1015-1019. doi: 10.1038/nsmb.2105

Chi, Y., Welcker, M., Hizli, A. A., Posakony, J. J., Aebersold, R. and Clurman, B. E. (2008). Identification of CDK2 substrates in human cell lysates. Genome Biol. 9:R149. doi 10.1186/gb-2008-9-10-r149

Clerici, M., Mantiero, D., Guerini, I., Lucchini, G., and Longhese, M. P. (2008). The Yku70-Yku80 complex contributes to regulate doublestrand break processing and checkpoint activation during the cell cycle. EMBO Rep. 9, 810-818. doi: 10.1038/embor.2008.121

Costelloe, T., Louge, R., Tomimatsu, N., Mukherjee, B., Martini, E., Khadaroo, B., et al. (2012). The yeast Fun30 and human SMARCAD1 chromatin remodellers promote DNA end resection. Nature 489, 581-584. doi: 10.1038/nature11353

Deans, A. J., Khanna, K. K., McNees, C. J., Mercurio, C., Heierhorst, J., and McArthur, G. A. (2006). Cyclin-dependent kinase 2 functions in normal DNA repair and is a therapeutic target in BRCA1-deficient cancers. Cancer Res. 66, 8219-8226. doi: 10.1158/0008-5472.CAN-05-3945

Dephoure, N., Zhou, C., Villén, J., Beausoleil, S. A., Bakalarski, C. E., Elledge, S. J., et al. (2008). A quantitative atlas of mitotic phosphorylation. Proc. Natl. Acad. Sci. U.S.A. 105, 10762-10767. doi: 10.1073/pnas.0805139105

Eapen, V. V., Sugawara, N., Tsabar, M., Wu, W.-H., and Haber, J. E. (2012). The Saccharomyces 
cerevisiae chromatin remodeler Fun30 regulates DNA end resection and checkpoint deactivation. Mol. Cell. Biol. 32, 4727-4740. doi: 10.1128/MCB.00566-12

Eid, W., Martinn, S., El-Shemerly, M., Ferretti, L. P., Peña-Diaz, J., König, C., et al. (2010). DNA end resection by CtIP and exonuclease 1 prevents genomic instability. EMBO Rep. 11, 962-968. doi: 10.1038/embor.2010.157

El-Shemerly, M., Hess, D., Pyakurel, A. K., Moselhy, S., and Ferrari, S. (2008). ATR-dependent pathways control hEXO1 stability in response to stalled forks. Nucleic Acids Res. 36, 511-519. doi: 10.1093/nar/ gkm1052

El-Shemerly, M., Janscak, P., Hess, D., Jiricny, J., and Ferrari, S. (2005). Degradation of human exonuclease $1 \mathrm{~b}$ upon DNA synthesis inhibition. Cancer Res. 65, 3604-3609. doi: 10.1158/0008-5472.CAN-04-4069

Enserink, J. M., and Kolodner, R. D. (2010). An overview of Cdk1controlled targets and processes. Cell Div. 5:11. doi: 10.1186/17471028-5-11

Errico, A., Deshmukh, K., Tanaka, Y., Pozniakovsky, A., and Hunt, T. (2010). Identification of substrates for cyclin dependent kinases. $A d v$. Enzyme Regul. 50, 375-399. doi: 10.1016/j.advenzreg.2009.12.001

Escribano-Díaz, C., Orthwein, A., Fradet-Turcotte, A., Xing, M., Young, J. T. F., Tkáč, J., et al. (2013). A cell cycle-dependent regulatory circuit composed of 53BP1-RIF1 and BRCA1-CtIP controls dna repair pathway choice. Mol. Cell 49, 872-883. doi: 10.1016/j.molcel.2013.01.001

Falck, J., Forment, J. V., Coates, J., Mistrik, M., Lukas, J., Bartek, J., et al. (2012). CDK targeting of NBS1 promotes DNA-end resection, replication restart and homologous recombination. EMBO Rep. 13, 561-568. doi: 10.1038/embor.2012.58

Finn, K., Lowndes, N. F., and Grenon, M. (2012). Eukaryotic DNA damage checkpoint activation in response to double-strand breaks. Cell. Mol. Life Sci. 69, 1447-1473. doi: 10.1007/ s00018-011-0875-3

Garcia, V., Phelps, S. E. L., Gray, S., and Neale, M. J. (2011). Bidirectional resection of DNA double-strand breaks by Mre11 and Exol. Nature 479, 241-244. doi: $10.1038 /$ nature 10515

Gravel, S., Chapman, J. R., Magill, C., and Jackson, S. P. (2008). DNA helicases Sgs1 and BLM promote DNA double-strand break resection.
Genes Dev. 22, 2767-2772. doi: $10.1101 / \mathrm{gad} .503108$

Hanks, S. K., and Hunter, T. (1995). Protein kinases 6. The eukaryotic protein kinase superfamily: kinase (catalytic) domain structure and classification. FASEB J. 9, 576-596.

Harper, J. W., and Adams, P. D. (2001). Cyclin-dependent kinases. Chem. Rev. 101, 2511-2526. doi: 10.1021/ cr0001030

Heyer, W.-D., Ehmsen, K. T., and Liu, J. (2010). Regulation of homologous recombination in eukaryotes. Annu. Rev. Genet. 44, 113-139. doi: 10.1146/annurevgenet-051710-150955

Holloman, W. K. (2011). Unraveling the mechanism of BRCA2 in homologous recombination. Nat. Struct. Mol. Biol. 18, 748-754. doi: 10.1038/nsmb.2096

Huertas, P. (2010). DNA resection in eukaryotes: deciding how to fix the break. Nat. Struct. Mol. Biol. 17, 11-16. doi: 10.1038/nsmb.1710

Huertas, P., and Jackson, S. P. (2009). Human CtIP mediates cell cycle control of DNA end resection and double strand break repair. J. Biol. Chem. 284, 9558-9565. doi: 10.1074/jbc.M808906200

Huertas, P., Cortés-Ledesma, F., Sartori, A. A., Aguilera, A., and Jackson, S. P. (2008). CDK targets Sae2 to control DNA-end resection and homologous recombination. Nature 455, 689-692. doi: 10.1038/nature07215

Ira, G., Pellicioli, A., Balijja, A., Wang, X., Fiorani, S., Carotenuto, W., et al. (2004). DNA end resection, homologous recombination and DNA damage checkpoint activation require CDK1. Nature 431, 1011-1017. doi: 10.1038 /nature02964

Jackson, S. P., and Bartek, J. (2009). The DNA-damage response in human biology and disease. Nature 461, 1071-1078. doi: 10.1038 /nature 08467

Jazayeri, A., Falck, J., Lukas, C., Bartek, J., Smith, G. C. M., Lukas, J., et al. (2006). ATM- and cell cycledependent regulation of ATR in response to DNA double-strand breaks. Nat. Cell Biol. 8, 37-45. doi: 10.1038/ncb1337

Karanam, K., Kafri, R., Loewer, A., and Lahav, G. (2012). Quantitative live cell imaging reveals a gradual shift between DNA repair mechanisms and a maximal use of HR in mid S phase. Mol. Cell 47, 320-329. doi: 10.1016/j.molcel. 2012.05.052

King, R. W., Deshaies, R. J., Peters, J. M., and Kirschner, M. W. (1996). How proteolysis drives the cell cycle. Science 274, 1652-1659. doi: 10.1126/science.274.5293.1652

Kosugi, S., Hasebe, M., Tomita, M., and Yanagawa, H. (2009). Systematic identification of cell cycle-dependent yeast nucleocytoplasmic shuttling proteins by prediction of composite motifs. Proc. Natl. Acad. Sci. U.S.A. 106, 10171-10176. doi: 10.1073/pnas.0900604106

Krejci, L., Altmannova, V., Spirek, M. and Zhao, X. (2012). Homologous recombination and its regulation. Nucleic Acids Res. 40, 5795-5818. doi: 10.1093/nar/gks270

Lazzaro, F., Sapountzi, V., Granata, M., Pellicioli, A., Vaze, M., Haber, J. E., et al. (2008). Histone methyltransferase Dot1 and Rad9 inhibit single-stranded DNA accumulation at DSBs and uncapped telomeres. EMBO J. 27, 1502-1512. doi: 10.1038/emboj.2008.81

Lee, D.-H., Pan, Y., Kanner, S., Sung, P., Borowiec, J. A., and Chowdhury, D. (2010). A PP4 phosphatase complex dephosphorylates RPA2 to facilitate DNA repair via homologous recombination. Nat. Struct. Mol. Biol. 17, 365-372. doi: 10.1038/nsmb.1769

Leng, M., Chan, D. W., Luo, H., Zhu, C., Qin, J., and Wang, Y. (2006). MPS1-dependent mitotic BLM phosphorylation is important for chromosome stability. Proc. Natl. Acad. Sci. U.S.A. 103, 11485-11490. doi: 10.1073/pnas.0601828103

Liaw, H., Lee, D., and Myung, K. (2011). DNA-PK-dependent RPA2 hyperphosphorylation facilitates DNA repair and suppresses sister chromatid exchange. PLOS ONE 6:e21424. doi: 10.1371/journal. pone. 0021424

Lieber, M. R. (2010). The mechanism of double-strand DNA Break Repair by the Nonhomologous DNA End-Joining Pathway. Annu. Rev. Biochem. 79, 181-211. doi: 10.1146/ annurev.biochem.052308.093131

Linding, R., Jensen, L. J., Ostheimer, G. J., van Vugt, M. A. T. M., Jørgensen, C., Miron, I. M., et al. (2007). Systematic discovery of in vivo phosphorylation networks. Cell 129, 1415-1426. doi: 10.1016/j.cell.2007.05.052

Liou, Y.-C., Zhou, X. Z., and Lu, K. P. (2011). Prolyl isomerase Pin1 as a molecular switch to determine the fate of phosphoproteins. Trends Biochem. Sci. 36, 501-514. doi: 10.1016/j.tibs.2011. 07.001

Longhese, M. P., Bonetti, D., Manfrini, N., and Clerici, M. (2010). Mechanisms and regulation of DNA end resection.
EMBO J. 29, 2864-2874. doi: 10.1038/emboj.2010.165

Malumbres, M., and Barbacid, M. (2005). Mammalian cyclindependent kinases. Trends Biochem. Sci. 30, 630-641. doi: 10.1016/j.tibs.2005.09.005

Manfrini, N., Guerini, I., Citterio, A., Lucchini, G., and Longhese, M. P. (2010). Processing of meiotic DNA double strand breaks requires cyclin-dependent kinase and multiple nucleases. J. Biol. Chem. 285, 11628-11637. doi: 10.1074/jbc.M110.104083

McKee, A. H., and Kleckner, N. (1997). A general method for identifying recessive diploid-specific mutations in Saccharomyces cerevisiae, its application to the isolation of mutants blocked at intermediate stages of meiotic prophase and characterization of a new gene SAE2. Genetics 146, 797-816.

Mimitou, E. P., and Symington, L. S. (2008). Sae2, Exo1 and Sgs1 collaborate in DNA double-strand break processing. Nature 455, 770-774. doi: $10.1038 /$ nature 07312

Mimitou, E. P., and Symington, L. S. (2009). Nucleases and helicases take center stage in homologous recombination. Trends Biochem. Sci. 34, 264-272. doi: 10.1016/j.tibs.2009.01.010

Morgan, D. O. (1997). Cyclindependent kinases: engines, clocks, and microprocessors. Annu. Rev. Cell Dev. Biol. 13, 261-291. doi: 10.1146/annurev.cellbio.13.1.261

Morin, I., Ngo, H.-P., Greenall, A., Zubko, M. K., Morrice, N., and Lydall, D. (2008). Checkpointdependent phosphorylation of Exol modulates the DNA damage response. EMBO J. 27, 2400-2410. doi: 10.1038/emboj.2008.171

Müller-Tidow, C., Ji, P., Diederichs, S., Potratz, J., Bäumer, N., Köhler, G., et al. (2004). The cyclin A1-CDK2 complex regulates DNA double-strand break repair. Mol. Cell Biol. 24, 8917-8928. doi: $\quad 10.1128 /$ MCB.24.20.89178928.2004

Nicolette, M. L., Lee, K., Guo, Z., Rani, M., Chow, J. M., Lee, S. E., et al. (2010). Mre11-Rad50Xrs2 and Sae 2 promote $5^{\prime}$ strand resection of DNA double-strand breaks. Nat. Struct. Mol. Biol. 17, 1478-1485. doi: 10.1038/nsmb.1957 Nimonkar, A. V., Genschel, J., Kinoshita, E., Polaczek, P., Campbell, J. L., Wyman, C., et al. (2011). BLM-DNA2-RPAMRN and EXO1-BLM-RPA-MRN constitute two DNA end resection machineries for human DNA break 
repair. Genes Dev. 25, 350-362. doi: 10.1101/gad.2003811

Niu, H., Chung, W.-H., Zhu, Z., Kwon, Y., Zhao, W., Chi, P., et al. (2010). Mechanism of the ATPdependent DNA end-resection machinery from Saccharomyces cerevisiae. Nature 467, 108-111. doi: 10.1038/nature09318

Oakley, G. G., and Patrick, S. M. (2010). Replication protein A: directing traffic at the intersection of replication and repair. Front. Biosci. 15, 883-900.

Olsen, J. V., Vermeulen, M., Santamaria, A., Kumar, C., Miller, M. L., Jensen, L. J., et al. (2010). Quantitative phosphoproteomics reveals widespread full phosphorylation site occupancy during mitosis. Sci. Signal 3, ra3. doi: 10.1126/scisignal.2000475

Paull, T. T. (2010). Making the best of the loose ends: Mrel1/Rad50 complexes and Sae2 promote DNA double-strand break resection. DNA Repair (Amst.) 9, 1283-1291. doi: 10.1016/j.dnarep.2010.09.015

Price, B. D., and D'Andrea, A. D. (2013). Chromatin remodeling at DNA double-strand breaks. Cell 152, 1344-1354. doi: 10.1016/j.cell. 2013.02.011

Prinz, S., Amon, A., and Klein, F. (1997). Isolation of COM1, a new gene required to complete meiotic double-strand break-induced recombination in Saccharomyces cerevisiae. Genetics 146, 781-795.

Sartori, A. A., Lukas, C., Coates, J., Mistrik, M., Fu, S., Bartek, J., et al. (2007). Human CtIP promotes DNA end resection. Nature 450, 509-514. doi: 10.1038/nature06337

Serrano, M. A., Li, Z., Dangeti, M., Musich, P. R., Patrick, S., Roginskaya, M., et al. (2013). DNA-PK, ATM and ATR collaboratively regulate p53-RPA interaction to facilitate homologous recombination DNA repair. Oncogene 32, 2452-2462. doi: 10.1038/onc.2012.257

Shao, Z., Davis, A. J., Fattah, K. R., So, S., Sun, J., Lee, K.-J., et al. (2012). Persistently bound $\mathrm{Ku}$ at DNA ends attenuates DNA end resection and homologous recombination. DNA Repair (Amst.) 11, 310-316. doi: 10.1016/j.dnarep.2011.12.007

Shi, W., Feng, Z., Zhang, J., GonzalezSuarez, I., Vanderwaal, R. P., Wu, X., et al. (2010). The role of RPA2 phosphorylation in homologous recombination in response to replication arrest. Carcinogenesis 31, 994-1002. doi: 10.1093/carcin/bgq035

Shiromizu, T., Adachi, J., Watanabe, S., Murakami, T., Kuga, T., Muraoka, S., et al. (2013). Identification of missing proteins in the neXtProt database and unregistered phosphopeptides in the PhosphoSitePlus database as part of the chromosome-centric human proteome project. J. Proteome Res. doi: 10.1021/pr300825v. [Epub ahead of print].

Siepe, D., and Jentsch, S. (2009). Prolyl isomerase Pinl acts as a switch to control the degree of substrate ubiquitylation. Nat. Cell Biol. 11, 967-972. doi: 10.1038/ncb1908

Steger, M., Murina, O., Hühn, D., Ferretti, L. P., Walser, R., Hänggi, K., et al. (2013). Prolyl isomerase PIN1 regulates DNA double-strand break repair by counteracting DNA end resection. Mol. Cell 50, 333-343. doi: 10.1016/j.molcel. 2013.03.023

Sun, J., Lee, K.-J., Davis, A. J., and Chen, D. J. (2012). Human $\mathrm{Ku} 70 / 80$ protein blocks exonuclease 1-mediated DNA resection in the presence of human Mrel1 or Mre11/Rad50 protein complex. J. Biol. Chem. 287, 4936-4945. doi: 10.1074/jbc.M111.306167

Symington, L. S., and Gautier, J. (2011). Double-strand break end resection and repair pathway choice. Annu. Rev. Genet. 45, 247-271. doi: 10.1146/annurevgenet-110410-132435

Tomimatsu, N., Mukherjee, B., Deland, K., Kurimasa, A., Bolderson, E. Khanna, K. K., et al. (2012). Exol plays a major role in DNA end resection in humans and influences double-strand break repair and damage signaling decisions. DNA Repair (Amst.) 11,
441-448. doi: 10.1016/j.dnarep. 2012.01.006

Tran, P. T., Erdeniz, N., Symington, L. S., and Liskay, R. M. (2004). EXO1-A multi-tasking eukaryotic nuclease. DNA Repair (Amst.) 3, 1549-1559. doi: 10.1016/j.dnarep.2004.05.015

Tsabar, M., and Haber, J. E. (2013). Chromatin modifications and chromatin remodeling during DNA repair in budding yeast. Curr. Opin. Genet. Dev. 23, 166-173. doi: 10.1016/j.gde.2012.11.015

Ubersax, J. A., Woodbury, E. L., Quang, P. N., Paraz, M., Blethrow, J. D., Shah, K., et al. (2003). Targets of the cyclin-dependent kinase Cdk1. Nature 425, 859-864. doi: 10.1038/nature02062

Wang, B., Matsuoka, S., Carpenter, P. B., and Elledge, S. J. (2002). 53BP1, a mediator of the DNA damage checkpoint. Science 298, 1435-1438. doi: 10.1126/science. 1076182

Wang, H., Shi, L. Z., Wong, C. C. L., Han, X., Hwang, P. Y.-H., Truong, L. N., et al. (2013). The interaction of CtIP and Nbsl connects CDK and ATM to regulate HR-mediated double-strand break repair. PLoS Genet. 9:e1003277. doi: 10.1371/journal.pgen.1003277

Wohlbold, L., Merrick, K. A., De, S., Amat, R., Kim, J. H., Larochelle, S., et al. (2012). Chemical genetics reveals a specific requirement for cdk2 activity in the DNA damage response and identifies nbsl as a cdk2 substrate in human cells. PLoS Genet. 8:e1002935. doi: 10.1371/journal.pgen.1002935

You, Z., Shi, L. Z., Zhu, Q., Wu, P., Zhang, Y.-W., Basilio, A., et al. (2009). CtIP links DNA double-strand break sensing to resection. Mol. Cell 36, 954-969. doi: 10.1016/j.molcel.2009.12.002

Yu, X., and Chen, J. (2004). DNA damage-induced cell cycle checkpoint control requires CtIP, a phosphorylation-dependent binding partner of BRCA1 C-terminal domains. Mol. Cell Biol. 24, 9478-9486. doi: 10.1128/MCB. 24.21.9478-9486.2004
Yu, X., Fu, S., Lai, M., Baer, R., and Chen, J. (2006). BRCA1 ubiquitinates its phosphorylationdependent binding partner CtIP. Genes Dev. 20, 1721-1726. doi: 10.1101/gad.1431006

Zhang, Y., Shim, E. Y., Davis, M., and Lee, S. E. (2009). Regulation of repair choice: Cdk1 suppresses recruitment of end joining factors at DNA breaks. DNA Repair (Amst.) 8, 1235-1241. doi: 10.1016/j.dnarep.2009.07.007

Zhou, B. B., and Elledge, S. J. (2000). The DNA damage response: putting checkpoints in perspective. Nature 408, 433-439. doi: 10.1038/35044005

Zhu, Z., Chung, W.-H., Shim, E. Y., Lee, S. E., and Ira, G. (2008). Sgs1 helicase and two nucleases Dna2 and Exol resect DNA double-strand break ends. Cell 134, 981-994. doi: 10.1016/j.cell.2008.08.037

Zou, L., and Elledge, S. J. (2003). Sensing DNA damage through ATRIP recognition of RPA-ssDNA complexes. Science 300, 1542-1548.

Conflict of Interest Statement: The authors declare that the research was conducted in the absence of any commercial or financial relationships that could be construed as a potential conflict of interest.

Received: 09 April 2013; paper pending published: 19 April 2013; accepted: 16 May 2013; published online: 03 June 2013.

Citation: Ferretti LP, Lafranchi L and Sartori AA (2013) Controlling DNAend resection: a new task for CDKs. Front. Genet. 4:99. doi: 10.3389/fgene. 2013.00099

This article was submitted to Frontiers in Cancer Genetics, a specialty of Frontiers in Genetics.

Copyright (c) 2013 Ferretti, Lafranchi and Sartori. This is an open-access article distributed under the terms of the Creative Commons Attribution License, which permits use, distribution and reproduction in other forums, provided the original authors and source are credited and subject to any copyright notices concerning any third-party graphics etc. 